\title{
ARTE E CONHECIMENTO EM OS PAPÉIS DO INGLÊS, DE RUY DUARTE DE CARVALHO
}

\author{
Felipe Grüne Ewald \\ (Universidade Estadual de Londrina)
}

\begin{abstract}
RESUMO
O presente texto dedica-se ao estudo de Os Papéis do Inglês, de Ruy Duarte de Carvalho, que busca marcar a legitimidade e o espaço do discurso etnográfico na constituição plena do romance. Abordo três aspectos congruentes e inter-relacionados. O primeiro nomeio genericamente como uma epistemologia, em função de a obra nos apresentar diferentes formas de conhecer e lidar com o mundo. A partir do lugar do antropólogo, o narrador propõe uma lógica de simetria e se distancia dos rumos tomados pelo meio acadêmico, voltando-se para a busca da subjetividade de modo relacional, em função dos outros. O segundo aspecto, atrelado ao primeiro, trata da construção da narrativa, o que é exposto tanto no conteúdo, como na forma. Aqui evidencia-se o uso constante de estruturas metanarrativas: o narrador suspende a narrativa a fim de retomá-la, reconsiderá-la e refletir sobre o caminho que ela irá tomar. Os dois aspectos anteriores dão forma a um terceiro, que consiste em uma proposição estética singular. Conclui-se que o romance mira uma discussão das subjetividades, sempre alçadas em uma relação, cuja experiência é relatada. O romance é formado pelos diferentes discursos, entre eles o etnográfico.
\end{abstract}

PALAVRAS-CHAVE: epistemologia; narrativa; arte.

\section{ABSTRACT}

The text is devoted to the study of Os Papéis do Inglês, by Ruy Duarte de Carvalho, which aims at defining the legitimacy and the space of the ethnographic discourse in the full constitution of the novel. Three congruent and interrelated aspects are discussed. The first one is generically named as epistemology, due to the fact that the novel introduces different ways of knowing and dealing with the world. From the standpoint of the anthropologist, the narrator proposes a conception of symmetry and distances himself from the classical racional academic epistemologies, aiming at a subjectivity comprehended in terms of relations, dependent on the other subjects. The second aspect, clearly connected to the first one, concerns the construction of the narrative, which is exposed both in the content and in the formal aspects. The constant use of metanarrative structures is noticed. 
The narrator suspends the narrative in order to resume it, rethink it and reflect about the courses it will take. The previous two aspects form a third one, which postulates a particular understanding of aesthetics. We come to the conclusion that Ruy Duarte discusses the subjectivities put in relation and reports this experience. The novel is composed of different discourses, being the ethnographic discourse one of them.

KEYWORDS: epistemology; narrative; art.

Pretendo neste artigo abordar alguns aspectos presentes em $O s$ Papéis do Inglês que parecem impulsionar Ruy Duarte de Carvalho a marcar a legitimidade e o espaço do discurso etnográfico na construção e constituição plena do romance. Ele é provocador na medida em que propõe discussões estéticas, epistemológicas e culturais ao enredar narrativa, antropologia, história e ficção.

Rita Chaves comenta a ligação entre ficção e ensaio, ciência e arte, documento e poética, e indica a:

presença de um discurso mesclado, elaborado sobre a atenuação das fronteiras entre os gêneros que o escritor pode cultivar. Diante delas, o leitor experimenta um sentimento afim, que é uma certa perplexidade nascida da dificuldade de distinguir na tipologia convencional a modalidade literária que tem diante dos olhos. (s/d)

Em meio à tensão incessante entre o ensaístico e o ficcional, o autor investe em proposições, não apenas em seu conteúdo discursivo, mas também pela própria construção formal da narrativa, ao discutir reiteradamente seu processo de elaboração, atraindo assim a atenção para a concretude do ato de narrar. Busca uma interseção possível entre a experiência concreta - "[sábios] partilham logo ali, no próprio acto de viver, tudo o que vivem..." - e o relato mediado das peripécias - "Pensava, e sabia que ainda havia de escrever sobre isso" (CARVALHO, 2009, p. 114). Talvez uma solução seja pensar a experiência através da linguagem narrativa. $\mathrm{O}$ autor parece postular o que busco nomear por uma estética da relação: a arte vivida por uma conjuntura imanente, acessada na materialidade, não a partir da confrontação com um modelo ideal transcendente.

Parece claro aceitar que todos nós, etnógrafos, escritores, informantes, e os textos resultantes da nossa atividade, constituímos e constituem produtos ativos de cultura. Poderíamos dizer que todos somos sujeitos culturais e objetos culturais. (MARTINHO, 2010, p. 10, grifo meu)

Com isso, fica posto o que se irá desenvolver aqui: entre as muitas questões presentes no livro, optei por explorar três aspectos congruentes, que se encontram imbricados e que tentarei separar provisoriamente, mantendo em vista, no entanto, que eles se encontram em permanente inter-relação. O primeiro nomearei genericamente como uma epistemologia, em função de a obra nos apresentar diferentes formas de conhecer e lidar com o mundo - a partir do lugar de antropólogo, o narrador propõe uma 
lógica de simetria. O segundo aspecto, atrelado ao primeiro, trata da construção da narrativa, o que é exposto tanto no conteúdo - a colagem de outros textos, a ambientação do seu personagem no cenário criado por outro autor -, como na forma - o uso constante de uma estrutura metanarrativa. Estes dois aspectos dão forma a um terceiro, que consiste em uma proposição estética singular, igualmente por meio formal e de conteúdo, já que a narrativa é carregada de argumentação ensaística.

Há assim algumas teses sendo defendidas, num flerte com modos de pensar arte e conhecimento distintos do ocidental e hegemônico e, no mínimo, complementares a este. Todos estes pontos serão desenvolvidos na sequência. Antes, no entanto, passarei a uma breve apresentação do livro.

\section{O ROMANCE}

Os Papéis do Inglês narra os deslocamentos de um antropólogo que, em meio ao trabalho etnográfico, envolve-se na busca de alguns papéis deixados por um inglês, de nome Archibald Perkings, o qual, no primeiro quartel do século XX, dizima seu acampamento e comete suicídio, numa região isolada no sul de Angola, então colônia portuguesa.

O livro é composto de trechos curtos de diário de campo, datados dos últimos dias do ano de 1999. O último registro se dá no dia primeiro de janeiro de 2000, sem haver nenhuma referência a esta virada. Ruy Duarte parece marcar com isso o descompasso daqueles cantões da África com o resto do mundo, que segue sem integrá-la ou reconhecê-la de fato, o que não é rotulado, nem como bom nem como ruim; é um tom de constatação. O narrador diz: "nesta África concreta que tu, e todo o mundo, tão pouco realizam no exacto fim deste século XX" (CARVALHO, 2009, p. 12).

Também compõem o livro trechos de narrativa que carregam um tom epistolar: há sempre uma referência a uma destinatária, a quem o narrador (em primeira pessoa) escreve para contar a estória. Subentende-se ser uma pessoa estranha ao ambiente e ao conteúdo do relato; alguém distante de Angola.

Uma curta narrativa de Henrique Galvão gera um mote inicial para a estória a ser imaginada e elaborada pelo narrador. A partir daí, acasos ligarão os personagens, tornando a busca pelo Inglês uma busca pessoal, de si.

Os demais desenvolvimentos da narrativa serão apresentados ao longo deste trabalho, pois a discussão a ser realizada envolverá o processo de construção do texto, já que me parece haver uma imbricação entre forma e conteúdo. Um reflete o outro, dando consistência ao romance.

\section{CONHECIMENTO}

O cabedal de referências teóricas e metodológicas assumidas pelo narrador-antropólogo está seguramente atrelado à forma de produção de conhecimento ocidental. Veja-se a respeito disso o longo recorrido histórico que ele empreende acerca dos princípios da antropologia e o surgimento de novos paradigmas sincrônicos em oposição aos históricos. É neste ambiente, da academia britânica, em plena London School of Economics, 
que ele insere o Inglês: "O ano anterior a esse [do suicídio de Perkings], o de 1922, foi retido pela história como o annus mirabilis do funcionalismo, com a publicação dos estudos do próprio Radcliff-Brown e de Malinovsky" (CARVALHO, 2009, p. 51).

No entanto, como veremos mais adiante, o narrador irá se alinhar com Perkings, que entra num processo de distanciamento e discordância com os rumos tomados pelo meio acadêmico e acaba por se rebelar.

E ainda: que em relação a todas as ciências, eu andava também era a experimentar uma imensa fadiga. Mesmo tendo em conta um qualquer mundo académico onde viesse a poder inscrever-se, de alguma forma, o tipo de conhecimento em que andava ali a chafurdar, teses já as tinha feito todas, por um lado, e no meio académico que era afinal o meu, o de Angola, não havia, institucionalmente até, espaço para o meu trabalho. (CARVALHO, 2009, p. 154-5)

A opção será trilhar vias alternativas de conhecimento, destacadas da ideologia mainstream ocidental. Nesse sentido, desejo inserir aqui uma discussão acerca de alternativas epistemológicas, embasadas principalmente no pensamento de Eduardo Viveiros de Castro, antropólogo brasileiro, que poderão auxiliar no entendimento da obra de Ruy Duarte de Carvalho.

Na epistemologia objetivista da modernidade ocidental, a categoria do objeto constitui o telos. Para conhecer é preciso objetivar, dessubjetivar, ou seja, reduzir ao máximo a parcela do sujeito presente no objeto. O Outro toma a forma de coisa. No pensamento ameríndio, o ideal é o inverso: "conhecer é personificar, tomar o ponto de vista daquilo que deve ser conhecido - daquilo, ou antes, daquele; pois o conhecimento xamânico visa um 'algo' que é um 'alguém', um outro sujeito ou agente. A forma do Outro é a pessoa" (VIVEIROS DE CASTRO, 2002, p. 358).

Boaventura de Sousa Santos (2004) lembra que não há uma maneira apenas de conhecer. No entanto, a epistemologia ocidental costuma se autoconferir o direito soberano de detentora dos meios para o conhecimento total do mundo e exclui qualquer outro modo. Viveiros de Castro, pelo contrário, dá reconhecimento a outras posturas e insere-as no pensamento acadêmico - como preconiza Santos -, sob o entendimento de que, na relação etnográfica, há posições distintas, não-hierarquizadas, as quais são intercambiáveis, numa relação simétrica. Como veremos adiante, Ruy Duarte busca caminhos similares em território africano.

Para construir a conceituação do perspectivismo, uma concepção retirada em parte da epistemologia nietzschiana, Viveiros opta pelo caminho da subjetivação xamânica. Enquanto a epistemologia objetivista reduz toda ação a uma cadeia de eventos causais, a epistemologia ameríndia prega que todo evento é uma ação, expressão da intencionalidade de algum agente, universalizando a atitude intencional, e portanto a produção artística e estética. Para ela, "o objeto da interpretação é a contra-interpretação do objeto" (VIVEIROS DE CASTRO, 2002, p. 360). Aqui se revela a simetria de que interpretar é interpretar o que o Outro interpreta a meu respeito.

A questão dos contrastes epistemológicos também pode ser abordada por uma colocação de Walter Mignolo (2004, p. 677): “a celebração 
das razões científicas [é], ao mesmo tempo, a negação de outras formas de conhecimento". Concluímos que o totalitarismo científico repudia os paradigmas diferenciais, oculta a diversidade epistêmica do mundo, impondo-se como única forma de conhecimento legítima, autodefinida como "ciência". Esta visão é válida para destacar as possibilidades heterogêneas, mas, se seguirmos rigidamente esta forma de reconhecimento relativista de distintos paradigmas, chegaremos a um paradoxo ao nos defrontarmos com o perspectivismo apresentado por Viveiros de Castro. Este, ao representar uma forma de conhecimento distinta, ao mesmo tempo propõe uma unificação epistemológica, de forma a evitar o relativismo, transferindo a variação apenas para o plano ontológico.

Assim, poderíamos afirmar que o relativismo ocidental é um multiculturalismo que admite uma diversidade de representações subjetivas e parciais a respeito de uma natureza externa e universal, indiferente à representação. Já o perspectivismo ameríndio é um multinaturalismo que propõe uma unidade de representação (apenas pronominal, como marcador enunciativo, relacional) aplicada a naturezas diversas. "Uma só 'cultura', múltiplas 'naturezas'; epistemologia constante, ontologia variável” (VIVEIROS DE CASTRO, 2002, p. 379.).

Não me parece que o narrador de Os Papéis do Inglês adote um multinaturalismo, nem tampouco se mostre um relativista ferrenho. Mas, a todo momento, ele se opõe ao entendimento objetivado, em busca da subjetividade de modo relacional, em função de outros.

Ninguém fala hoje de darwinismo, é certo. Mas o iluminismo e evolucionismo estão implícitos em toda a produção ideológica e intelectual que vigora e ainda e sempre omnipresentes e dominantes, cientes já dos seus maiores pecados do passado, na aferição da qualidade dos homens segundo escalas físicas, primeiro, e depois segundo uma hierarquização das culturas, mas a fundamentar o mesmo espírito de império, ainda quando disfarçados de um igualmente abjecto paternalismo que confere a uns o direito de decidir, benemérita e providencialmente, pelos outros e em nome dos outros, os ignorantes e os atrasados, os coitados. E esses uns e outros somos todos nós, uns para os outros e por aí fora e sempre em função do ganho do outro.

(CARVALHO, 2009, p. 151, grifo meu)

Ao usar a primeira pessoa do plural, compromete a si e aos outros, envolve a todos nas responsabilidades. Vem à tona a ideia, em interseção com Viveiros de Castro, de que interpretar é interpretar o que o outro interpreta de mim. E é assim que ele irá se imbuir de si através do Inglês e das 'comunidades' com que convive nas andanças em campo. A relação simétrica, em que conhecimentos são desenvolvidos mutuamente, entre nativos e antropólogo envolve uma lógica em que se admite que ambos os lados pesquisam e introduzem suas concepções. Ou seja, diferentemente de uma perspectiva unilateral, em que apenas a academia pesquisa.

Justamente esta unilateralidade move a revolta de Perkings, o qual alega que o uso do conhecimento antropológico pela administração colonial

só era defensável desde que ultrapassasse a concepção, sustentada pelos gestores do império, de que um tal saber haveria sobretudo de servir a acções de domínio por parte de quem estava a levar civilização a povos atrasados, e 
logo assim se obrigava a dispensar-lhes benefícios nem que fosse à força. E já que a expansão da civilização, da cultura e da lógica europeias era de facto imparável, estava no curso das coisas, o conhecimento dos antropólogos deveria aproveitar então à mudança integrada e não à redutora domesticação do indígena. (CARVALHO, 2009, p. 50, grifo meu)

A proposição de uma "mudança integrada" parece indicar que, se o ocidente chegaria a estas partes de África e travaria relação com os povos nativos, então que os conhecimentos destes também fossem trazidos para a prática ocidental. As mudanças ocorreriam para ambos os lados, ao invés da imposição redutora que arrasta aqueles tomados por primitivos e incultos.

A leveza e tácita sensibilidade para se fazer receptivo parte de um exemplo narrado a respeito do próprio Inglês:

Da terceira vez, finalmente, foi de kissange que o Ganguela se apresentou, um desses kissanges dos mais completos, com caixa grande de cabaça antiga. Tomou a posição habitual, ensaiou o tom já na primeira pausa, verteu no ar o choro das palhetas, prolongou a escorrência, deteve o fluxo com um remate brusco. O Inglês endireitou o corpo, firmou-se com força na perna esquerda para dar melhor apoio ao ombro do Ganguela, fixou-se na pauta e [com o som do violino] rasgou as horas, crepusculares, mornas ainda, no fim da tarde nos confins do Kwando.

Uma importante alteração ao programa viria a darse quando, na estação seguinte, o Inglês passou a vir acompanhar, na sanzala, os solos de kissange do Ganguela, surdina morosa em noites de lua e frias, e nos intervalos de alguns trechos mais sentidos era o lancinante contraponto do stradivarius que vinha dilacerar o peito de tantos homens, de tanta raça e tão sós. (CARVALHO, 2009, p. 79)

Aqui se observa a lógica intercambiável, em que a ação deixa o ambiente do Inglês e passa ao do Ganguela, mudando também o papel ocupado pelo respectivo instrumento musical: o solo e o acompanhamento. Note-se o verbo "vir" utilizado pelo narrador, que insinua uma perspectiva a partir do nativo, olhando para o inglês, interpretando-o como alguém de dentro da cultura local. Mas o principal é o tom lírico predominante - usado para descrever ambas as manifestações musicais - que serve para sugerir uma discussão intrincada, de uma simetria de conhecimentos, em que ambos os lados lançam interpretações e sentimentos.

Para Sandro Ornellas (2009, p. 193), Ruy Duarte se despe "da autoridade de uma hiperdefinição literária ou antropológica”; ele abandona "a autoridade que podemos nomear de moderna, ligada a saberes cuja autoria, do tipo objetiva e científica, almeja apagar do seu campo qualquer vestígio de subjetividade, qualquer índice da presença, do corpo e da sua incontrolável exterioridade". E assim, o sujeito ficcional se coloca num certo isolamento dentro da sociedade angolana, afastado da academia e da lógica de aproveitar as oportunidades econômicas, e também externo às comunidades com as quais convive. 
Da sorte, do destino até mesmo mais imediato, destas "comunidades"? Entrarão no século XXI sem que as dinâmicas de uma economia fundamentada na gestão dos equilíbrios se tenha alterado profundamente. [...] Ninguém hoje mais ou menos tributário do senso comum consegue deixar de associar despojamento tecnológico a miséria. Pôr isso em causa seria confrontar a redenção igualizante da ideologia do progresso [...] ao elogio politicamente retrógrado, de uma prosperidade possível nos terrenos do equilíbrio e da redistribuição. (CARVALHO, 2009, 150)

No que concerne à subjetividade relacional, pela qual o antropólogo, através da interpretação do Inglês, interpreta a si mesmo, há uma proposição emblemática na narrativa: "Ao fim e ao cabo o que mais nos toca, ou o que mais nos interessa, não é o que mais ou melhor diz, mas onde melhor nos vemos" (CARVALHO, 2009, p. 93, grifo meu). Ocorre uma escalada no processo de identificação em que, de certa forma, o narrador torna-se o próprio Inglês, confunde-se com ele, verifica a existência de si em função da do outro. Os papéis do Inglês, afinal, terminariam por ser seus, recebidos por herança de seu pai, que os havia comprado ao Ganguela. Mas além disso sua própria escrita, o livro que acabamos por ler, são também os papéis do Inglês, porque são os seus, do narrador; são o seu rastro.

Acompanhamos a confusão tomar conta: "o que estava a apoderar-se do branco desvalido que estava a ir ali no meu lugar era uma imensa fadiga, mais grave que a de Archibald Perkings em Londres" (CARVALHO, 2009 , p. 112). Subjetividade e alteridade se veem mescladas: é o narrador e é também o Inglês.

Era eu, bem entendido, mas não o mesmo que está agora a contar-te uma estória. A minha corrida atrás de uns papéis, do meu pai, mas que podiam ser também os do Inglês da estória do Galvão, gera a acção que há de resultar uma segunda estória. [...] Vou ter que contarme, tratar-me, pois, enquanto personagem dessa estória. (CARVALHO, 2009, p. 36)

Por meio de uma linhagem de aquisições e parentescos, os papéis são do inglês, do pai do narrador e do próprio, mas também do Ganguela do Coice, do avô do Paulino e deste, assistente do narrador, por uma outra linhagem. Todos afinal se mesclam, se confundem, estão numa deriva identitária, ocupando posições relativas um ao outro, nunca independente ou unívoca. É a discussão da complexidade perpassando diferentes níveis: cultural - os traços distintivos e homogêneos que contrastam com os outros homens -; estético - a heterogeneidade dos discursos e 'gêneros' que perfazem o romance -; literário - a instabilidade e insuficiência da fronteira nacional para a denominação de uma literatura, afinal há traços do inglês, do português, do angolano e do kuvale. Logo, o romance de Ruy Duarte afirma que o que é possível alcançar é uma discussão das subjetividades, sempre alçadas em uma relação, ou seja, dentro de uma conjuntura espaço-temporal. $\mathrm{O}$ autor não parece perseguir a marca de uma angolanidade ${ }^{1}$, ao menos não uma idealizada. Seu esforço talvez esteja na construção de um quadro complexo de como se constitui aquela região geográfica.

Não se assemelha à intuição lírica do moçambicano Mia Couto, nem à denúncia do angolano Luandino Vieira. Ocupa justamente a posição do antropólogo: é um deslocado que reflete sobre o todo, pela característica reflexiva e crítica de uma etnografia bem realizada em que ele mesmo se apresenta. 
Ana Maria Martinho ressalta um contraste entre Uanhenga Xitu e Ruy Duarte de Carvalho:

Xitu tem sido inquestionavelmente admitido no cânone angolano, mas não tanto no exterior do país. O oposto parece ocorrer com Carvalho. As razões não são óbvias, mas parecem estar relacionadas com a acomodação das modalidades de representação nacional que ou coincide com o espectro de uma recepção de proximidade ou o contradiz. (MARTINHO, 2010, p. 16)

Ruy Duarte tem um discurso mais próximo do científico, não investe na reinvenção do idioma; trabalha com ele. Tampouco idealiza o país, e assim não delineia um projeto de nação claro, e, muito menos, unívoco. Não se trata de uma "literatura nacional", aqui pensada como um discurso que alce as diferenças e contrastes a um centro comum, com intuito unificador, delineador de uma identidade. No intuito de qualificar a obra, poderíamos chamá-la de uma "literatura cultural", numa referência ao seu intento de afirmar a diferença e ressaltar os traços distintivos locais. É claro que, ao expor os modos de vida de populações olvidadas de Angola, coopera-se na construção de um quadro amplo da nação. No entanto, meu argumento é de que isso se faz sem um olhar integrador. Apresenta-se um enfoque etnográfico, com a descrição de uma cultura local, situada dentro de uma região geográfica e não de uma divisão política.

\section{CONSTRUÇÃO DA NARRATIVA}

Atrelado a esta modalidade de relação com o pensamento alheio e a constituição da identidade do próprio livro, nota-se que o processo de construção da narrativa, mais do que o produto final, ocupa um espaço central em Os Papéis do Inglês. Todo o texto se faz em aproveitamento de outros discursos e modos diversos, seja o, digamos, texto-base de Henrique Galvão, sejam as possibilidades estéticas atreladas ao cotidiano - como veremos na próxima seção -, sejam mesmo obras de Céline ou Conrad. Exemplo disso é o aproveitamento da ambiência de um romance deste último autor para inserir o Inglês:

A misty rain settled like silvery dust on clothes, on moustaches; wetted the faces, vanished the flagstones, darkened the walls, dripped from umbrellas... Alvan Hervey, na novela do Conrad (The Return) onde te estou a situar o meu Archibald Perkings, já deste conta, não vai primeiro a ponte de Waterloo nenhuma, segue directamente para casa, onde o espera o drama que dará lugar à estória que protagoniza. (CARVALHO, 2009, p. 53)

À parte este entrelaçamento intertextual no domínio do conteúdo, podemos ver evidência maior da constante construção narrativa, pela dimensão da forma, com o uso constante de uma estrutura que chamarei de metanarrativa. Acerca desta, desejo levantar adiante algumas considerações teóricas prévias.

Ao se observar as circunstâncias de produção da narrativa, um dos aspectos que podem ser analisados é a ocorrência da metanarrativa, isto é, a demonstração da não-transparência da realização da linguagem. Atra- 
vés da elucidação da metanarrativa pode-se compreender como se forma o espaço enunciativo, como ocorre a presença do locutor em sua enunciação, no "ativo processo de negociação no qual os participantes examinam reflexivamente o discurso na forma como ele está emergindo" (BAUMAN e BRIGGS ${ }^{2}$ apud HARTMANN, 2005, p. 130). A metanarrativa auxilia o narrador a corrigir e reafirmar sua narrativa, expondo sua relação constante e necessária com ela e com os interlocutores. Isto nos remete novamente à lógica relacional, já explicitada na discussão sobre o conhecimento.

Seguindo a perspectiva do dialogismo bakhtiniano, temos que a língua se realiza pela negociação necessária com o outro na construção do discurso. Assim se processa a "comunhão fática", proposta por Malinovski e lembrada por Jakobson (1969), a qual se caracteriza como uma maneira de o discurso, sob a forma do diálogo, estabelecer uma situação colaborativa entre os indivíduos.

Na mesma linha do dialogismo de Bakhtin coloca-se Authier-Revuz (1998), ao estabelecer formas de heterogeneidade, mostrada e constitutiva. O narrador faz uso da metanarrativa como forma de ajuste da narrativa para si mesmo (no uso que faz da reflexividade) e, concomitantemente, em função da - ou talvez em conseqüência da - negociação com o outro que, forçosamente, habita seu discurso. Reajusta assim o engendramento da comunhão fática.

Authier-Revuz (1998, p. 15) pensa o campo metaenunciativo como a: "auto-representação do dizer se fazendo, em que o discurso sobre a prática da linguagem conjuga os dois planos da prática e da representação - como parte desta prática". Ela expõe "a relação entre as trocas em diálogo e as estruturas reflexivas, caracterizadas como manifestação de um autodialogismo inerente à enunciação" (1998, p. 20). É desta reflexividade que o narrador-antropólogo de Os Papéis do Inglês faz uso quando põe em prática as estruturas do que tomo aqui por metanarrativa, negociando sentido e espaço com o outro em sua narrativa. Esta negociação dinâmica que afasta e aproxima é importante para compreender o mecanismo da metanarrativa. É este também o movimento que vislumbro no livro de Ruy Duarte, com o narrador sempre medindo distâncias e proximidades com os outros que, afinal, o constituem.

Authier-Revuz caracteriza a metaenunciação como opacificante (não-transparente) porque aquele que usa a linguagem deixa de ter aparência de um sujeito puro, que dominaria todo o espaço de uso da língua. É um sujeito que se intimida diante da presença necessária do outro em seu discurso (dialogismo) e busca, assim, expor sua presença, negociando os espaços com este outro.

Outro olhar é oferecido por Bauman (1986), que entende metanarração como os dispositivos que classificam ou comentam: 1. a própria narrativa, sua mensagem, forma, função e discurso; 2 . os componentes ou a condução do evento narrativo, incluídos aí participantes, organização e ação. Ele acrescenta que, estritamente falando, não há narração sem metanarração.

Exatamente nos termos discutidos acima, de uma constante discussão e negociação acerca dos rumos a serem tomados na narrativa - e em congruência com a necessária relação entre conhecimentos - surgem no texto de Ruy Duarte longos trechos ilustrativos. Abaixo, um exemplo 
dessa situação em que o narrador suspende a narrativa a fim de retomá-la, reconsiderá-la e refletir sobre o caminho que ela irá tomar.

A presença de um gentleman inglês naquelas paragens, e nas condições em que Galvão o colocava, acabou pois por desencadear o derrame imaginativo que me permitiu associar-lhe a imensa fadiga de Archibald Perkings perante o meio académico em que circulava e o desarranjo conjugal que precipitou a sua saída de Londres. Mas também o abate do Grego, primeiro, e depois o suicídio que Archibald cometera, ocorriam, na crónica de Galvão, desprovidos de substância capaz de sustentar a dramaticidade das ocorrências. A discussão que Galvão lhes imputa e o abismo entre as personalidades e a educação de Perkings e do Grego dificilmente poderiam, numa narrativa, tornar credível o abate deste. Tão-pouco o alheamento com que a autoridade portuguesa tinha encarado o caso dava cobertura satisfatória ao suicídio do Inglês. A figura do Barão Belga, que Galvão introduz já depois da morte do Grego, também por outro lado me colocava problemas. E foi a partir daí, julgo, que o curso de tanta insatisfação se apoderou de mim até me impor uma versão nova para a cadeia dos eventos e das causalidades que a pouco e pouco, afinal, assumia os contornos de uma estória muito mais complexa. (CARVALHO, 2009, p. 61)

Silveira e Tarouco (2008, p. 75), seguindo Gardner ${ }^{34}$, adotam o termo metaficção, o qual "quer dizer ficção que, tanto no estilo quanto no tema, investiga ficção. [...] uma narrativa que chame a atenção sobre seus métodos e mostre ao leitor o que está acontecendo com ele enquanto lê”. As autoras aludem ainda a um outro propósito para o uso desta ferramenta de composição:

A metaficção surge, portanto, em Os papéis do Inglês como uma tentativa de superar o peso da tradição do romance português. Desse modo, a obra de Ruy Duarte subverte não apenas o ponto de vista eurocêntrico, mas os elementos de composição narrativa da obra de Henrique Galvão intriga, personagens, ação -, tendo como estratégia final a elaboração de um jogo intelectual com a linguagem e com a memória literária e artística, tratando da literatura portuguesa e da literatura africana de língua portuguesa. (SILVEIRA \& TAROUCO, 2008, p. 76)

Já Ornellas (2009, p. 198) crê que a subjetividade irrompe através de um metadiscurso que comenta a própria irrupção da subjetividade e suas conseqüências". Tal pode ser o caso do trecho abaixo, em que encontramos insinuações, a simulação de uma narrativa que se faz sempre em forma metanarrativa e negocia subjetividades:

Por essa altura eu já tinha inventado o tal enredo praticamente completo para minha estória de suicídio e crime, que ia elaborando a partir dos elementos que Galvão tinha introduzido na sua crónica sobre o estranho caso do Inglês 'que não suportava mulheres brancas'. [...] 
Cenas, situações, encadeamentos e desenlaces, que vinham sobretudo preencher os vazios das versões de que dispunha, passaram então a ocorrer-me com grande frequência e nitidez. (CARVALHO, 2009, p. 45-6)

\section{ARTE}

Chegamos assim ao domínio da arte e da proposição estética. Esta se vê em franca consonância com os aspectos já apontados anteriormente, tem seu funcionamento ativo dentro deles. A argumentação que venho fazendo alude à necessidade de se ter as subjetividades em franca relação, $o$ que tentei ilustrar com trechos do romance de Ruy Duarte de Carvalho. Os processos de produção de conhecimento devem obedecer a uma lógica de simetria, sendo que a estruturação da identidade subjetiva só se pode fazer pela confrontação com o alheio. É no alheio que estamos presentes.

Para constatar a singularidade da proposta estética presente em Os Papéis do Inglês, apoio-me no filósofo francês Michel Onfray (2010, p. 80), para quem o ready-made de Duchamp ensina que "não existe verdade intrínseca da obra de arte e do Belo, mas uma verdade relativa e conjuntural. A arte não procede de um mundo inteligível, mas de uma configuração sensível, de um dispositivo sociológico". Onfray (2010, p. 96) defende que a busca deve ser em direção ao "gosto pelo real e pela matéria do mundo, o desejo de imanência e deste mundo, a paixão pela textura das coisas, o aveludado dos materiais, a carnação das substâncias". Aqui neste preceito se encaixa uma proposta estética capital na obra de Ruy Duarte.

A distância entre aquelas sandálias, que ao fim da manhã estariam prontas, novas, de couro cru, rude, e as que o próprio Ketia-Ketia calçava então, moídas pelo tempo e pelos seus andares, eis o que me interpelava. O objecto impregnado pela relação do uso. É à volta disso que há-de residir toda a carga que empresta tamanho valor àquelas peças, de uso quotidiano, imediatamente perecíveis nestas sociedades, quando são introduzidas nos circuitos da arte e o mercado internacional depois preserva e valoriza como tesouros. Uma cabaça para bater o leite, aqui, nova ainda mas aparelhada já para prover à sua função, e até adornada, tem já inscrito nela todo o investimento criativo que compete a uma obra de arte. Mas só o uso útil que se lhe vai extrair há-de conferir-lhe estatuto de coisa com valor plenamente simbólico. E, ainda assim, ninguém irá poupá-la ao uso, seria negá-la a ela e ao seu valor real, até que um dia quebre e o tempo normal a extinga depois. (CARVALHO, 2009, p. 140)

Neste trecho se enuncia a concretude, a perecibilidade, a imanência conjuntural aglutinadas neste par de sandálias; o valor encontra-se no uso, o investimento criativo não visa à ascensão a um modelo de Belo transcendente no qual se mirasse. O objeto, investido da carga subjetiva que o produz, apenas obtém sentido pleno se integrado ao manejo cotidiano, a um plano histórico de existência material. 
Ornellas levanta a questão da necessidade de reconsideração do conceito de poesia estritamente preso à concepção ocidental, que ignora a heterogeneidade das possibilidades. Ele alude à noção de etnopoética, a qual:

contribui fortemente para desobstruir o conceito demasiado restrito de poesia no ocidente, fazendo coro, por outras vias, ao discurso contemporâneo da diversidade cultural com uma noção aproximada de diversidade poética. A etnopoética propicia muito precisamente a desfolclorização dessas populações ao articular uma forma de encontro desierarquizado entre culturas. (ORNELLAS, 2009, p. 204)

Isso sugere o acompanhamento de outra proposta de Onfray (2010, p. 95): "repolitizar a arte [em detrimento da transcendência asséptica] (não com uma arte política no sentido militante do termo) supõe a injeção de um conteúdo capaz de gerar um agir comunicativo". Ruy Duarte realiza uma arte política, sem ser militante, alcançando, pelo contrário, uma perspectiva crítica, expondo as contradições, próprias e alheias. $\mathrm{O}$ próprio livro pode funcionar sob este preceito estético, já que está imbuído de uma carga subjetiva intensa, de um sujeito que se põe a negociar com o alheio que o reflete, tanto no conteúdo - a destinatária, os personagens, outros autores, o leitor, o próprio Inglês com quem passa a se confundir -, como na forma - a constante retomada e reconsideração da narrativa e novamente o leitor que manuseia a obra.

\section{RE-ENTRELAÇAMENTO}

A arte está no modo de relação: a sandália tem valor no uso! O que o narrador faz é explorar modos de relação, em que a própria relação tem valor forte, alternativa ao puro individualismo - não à subjetividade. O que Ruy Duarte propõe com a escrita é uma busca de variedades de relação ampla, com o mundo como um todo, não apenas a relação entendida entre pessoas. Onfray (2010, p. 114) lembra que "a humanidade surge num homem não com a sua forma (humana), mas com sua relação (humana) com o mundo". O próprio processo de identificação - profunda, ainda que sutil e apenas insinuada - entre o narrador e o Inglês é indício dessa necessária relação - como vimos em Viveiros de Castro e Authier-Révuz. A relação está imbricada na própria construção da narrativa, que vai revelando a escalada de identificação.

O romance se aproxima muito de um relato etnográfico, que é justamente a escrita da experiência, a partir dela e da relação travada. $\mathrm{Na}$ etnografia não observa de fora um fenômeno; é preciso participar deste fenômeno pra compreendê-lo; é experiência que se busca, não um valor estético transcendente. Isso se projeta na construção da narrativa, que adota uma linguagem próxima do texto antropológico. A proposta não é uma recriação estética de falas e atos, uma representação da oralidade, mas o relato da própria experiência da relação. A defesa é de que isso cabe sim dentro da literatura, especialmente num "gênero" como o romance. Claro que juntamente há uma fabulação, uma criação de mundos possíveis, mas 
não que isso seja a parte de literatura que se possa destacar do texto, em meio a outros discursos: todos os discursos compõem o romance. Além disso, esta elocubração de mundos possíveis não é traço distintivo e exclusivo da literatura: há um espaço borrado em que se encontra também, por exemplo, o discurso da história - antes negado, pela ciência positivista, e agora escancarado, pela história cultural - como se pode notar no livro $O$ queijo e os vermes, de Carlo Ginzburg -, em que a reconstrução histórica se dá pelas conjecturas e recriações especulativas. Todos se cruzam no terreno da narrativa. Se todos estão imbricados, então é mais um indício de que o sentido está na relação de uso.

O esquema de estruturação do romance de Ruy Duarte, quando opta pela configuração de uma história em que o narrador, ao invés de apenas narrar, discute como a narrativa deve ser contada, aponta para a centralidade do processo, de uma experiência que está sempre a se fazer, tem sua materialidade, sua dimensão histórica constantemente reafirmada. Ou seja, a própria estratégia narrativa aponta para uma concepção estética da imanência, o que também se insinua em alguns trechos.

A própria utilização de mecanismos metanarrativos, ou seja, a discussão da narrativa introduzida nela mesma, é indício da concepção estética imanente e conjuntural. Tal mecanismo é uma forma de reconhecimento e explicitação da heterogeneidade do discurso, de que não o habitamos sozinhos, ele também é constituído de outro (a dialogia de Bakhtin); uma maneira de demonstrar que o sentido se faz através de uma relação que está sendo travada. Logo, dentro de uma conjuntura material, fora da transcendência.

\section{REFERÊNCIAS BIBLIOGRÁFICAS}

AUTHIER-REVUZ, Jaqueline. Palavras Incertas: as não-coincidências do dizer. Trad. de Claudia R. Castellanos Pfeiffer et al. Campinas: UNICAMP, 1998.

BAUMAN, Richard. Story, Performance and Event: contextual studies of oral narrative. Cambridge University Press, 1986.

CARVALHO, Ruy Duarte. Os Papéis do Inglês - ou o Ganguela do Coice. São Paulo: Companhia das Letras, 2009.

CHAVES, Rita. Ruy Duarte de Carvalho: antropologia e ficção na representação do mundo. Disponível em: http://www.casadasafricas.org.br/ site/index.php?id=banco_de_textos\&sub=01\&id_texto=299. Acesso em: 05jan2011.

GUINZBURG, Carlo. Os queijos e os vermes: o cotidiano e as idéias de um moleiro perseguido pela inquisição. Trad. de Maria Betânia Amoroso. São Paulo: Companhia das Letras, 2006.

HARTMANN, Luciana. Performance e experiência nas narrativas orais da fronteira entre Argentina, Brasil e Uruguai. In: Horizontes Antropológicos. Porto Alegre, ano 11, n. 24, jul/dez, p. 125-153, 2005. 
JAKOBSON, Roman. Lingüística e Comunicação. Trad. de Izidoro Blikstein e José Paulo Paes. São Paulo: Cultrix/USP, 1969.

MARTINHO, Ana Maria Mão de Ferro. Memória e experiência etnográfica - literatura, cultura, representações. In: Mulemba. Rio de Janeiro, v.1, n. 3, p. 4 -18, jul./dez. 2010.

MIGNOLO, Walter D. Os esplendores e as misérias da "ciência": colonialidade, geopolítica do conhecimento e pluri-versalidade epistémica. In: SANTOS, Boaventura de Sousa (org.). Conhecimento prudente para uma vida decente. São Paulo: Cortez, 2004.

ONFRAY, Michel. A potência de existir: manifesto hedonista. Trad. Eduardo Brandão. São Paulo: WMF Martins Fontes, 2010.

ORNELLAS, Sandro. Ruy Duarte de Carvalho em transumância pelos discursos. In: Eutomia. Recife, ano II, n.1, p. 191-211, 2009.

SANTOS, Boaventura de Sousa. Introdução. In: (org.). Conhecimento prudente para uma vida decente. São Paulo: Cortez, 2004.

SILVEIRA, Regina da Costa da \& TAROUCO, Elisângela. Os papéis do Inglês e O vélo d’oiro: diversidades do real. Letras de Hoje. Porto Alegre, v. 43, n. 4, p. 73-77, out./dez. 2008.

VIVEIROS DE CASTRO, Eduardo. Encontros (org. Renato Sztutman). Rio de Janeiro: Beco do Azougue, 2008.

Perspectivismo e multinaturalismo na América indígena. In: __. A inconstância da alma selvagem - e outros ensaios de antropologia. São Paulo: Cosac Naify, 2002.

\section{NOTAS}

1 Quando afirmo que, no texto, não se persegue uma marca de angolanidade, refiro-me ao fato de que não se almeja - e até mesmo se repudie - a unificação forçada a um traço homogeneizador que se manifeste desde um centro hegemônico. No texto de Ruy Duarte, o traço que se apresente como definidor do momento atual de Angola talvez seja a necessidade de tirar proveito, a todo e qualquer custo, do desenvolvimento econômico e alcançar uma posição social de status elevado. É exatamente contra isso que o narrador se rebela; é disso que quer se separar. Ele se mostra hostilizado por não obedecer a este traço e, pelo contrário, identificar-se com a população local. Além disso, afirmo que o narrador não persegue uma marca de angolanidade, pois, a meu ver, não busca explicitamente tornar cosmopolita o discurso regional; apenas o expõe tentando manter o ponto de vista local, numa retórica muito mais próxima ao relato antropológico.

2 Cf. BAUMAN, R./ BRIGGS, C. Poetics and performance as critical perspectives on language and social life. Annual Review of Anthropology. Palo Alto, v.19, p.58-88, 1990.

3 Cf. GARDNER, John. A arte da ficção: orientações para futuros escritores. Trad. de Raul de Sá Barbosa. Rio de Janeiro: civilização Brasileira, 1997. p. 120-121. 